\title{
Review of 500 migraine cases treated with combination of antidepressant \& CBT \& specific group of dietary supplement with 6 month follow up
}

VK Goyal

From The European Headache and Migraine Trust International Congress

London, UK. 20-23 September 2012

Migraine is a condition which consumes maximum revenue of a family, state \& nation \& still the suffering goes on. In the world millions are suffering from Migraine .. \& having pain killer medicine \& suffering from their side effect like kidney failure etc Migraine sufferers may have depression deep down... but psychiatry being a stigma very few sufferer goes for consultation to psychiatrist. History of migraine needs a long time to listen \& the ability to listen, .... which normally a psychiatrist does not have time to listen the painful past \& long details without getting revenue - or fee or financially paid for - so depression goes unnoticed. Depression assessment scale -although available - but very few psychiatrist has a team work in India \& most of the countries.

\section{Purpose}

1 . To see that by treating depression \& adding specific group of dietary supplements - is there any effect on frequency severity \& relapse? 2 . Frequency of pain killer can it be reduced \& patient be saved from kidney failure?

\section{Methods}

1. Used exclusion criteria ..... where no other cause of migraine found...all investigation within norm. 2. After assessment treated with antidepressant \& CBT \& specific group of dietary supplememt. In follow up video of their statement regarding frequeny was noted \& use of pain killer was recorded.

\section{Result}

1. 50 patients dropped out of the study. 2.450 completed the study. 3. $90 \%$ of patients reported a $90 \%$ reduction in the use of pain killer. $4.100 \%$ reported that CBT helped them. $5.10 \%$ of patients reported a mixed picture of attacks but reported reduced severity.

\section{Conclusion}

Migraine patient may have depression underlying which if addressed can be a useful method to reduce severity of migrane attacks. If stigma of mental health or depression can be reduced - will benefit migraine patient. Nti depressant therapy coupled with CBT \& specific group of dietary supplement plays an important role in treatment of migraine .

Published: 21 February 2013

doi:10.1186/1129-2377-14-S1-P186

Cite this article as: Goyal: Review of 500 migraine cases treated with combination of antidepressant \& CBT \& specific group of dietary supplement with 6 month follow up. The Journal of Headache and Pain 2013 14(Suppl 1):P186. 